\title{
Extracorporeal ultrafiltration for acute heart failure: patient selection and perspectives
}

This article was published in the following Dove Press journal: Vascular Health and Risk Management

\author{
Valentina Milazzo \\ Nicola Cosentino \\ Giancarlo Marenzi \\ Intensive Cardiac Care Unit, Centro \\ Cardiologico Monzino, I.R.C.C.S., \\ Milan, Italy
}

\begin{abstract}
Most patients presenting with acute heart failure (AHF) show signs and symptoms of fluid overload, which are closely associated with short-term and long-term outcomes. Ultrafiltration is an extremely appealing strategy for patients with AHF and concomitant overt fluid overload not fully responsive to diuretic therapy. However, although there are several theoretical beneficial effects associated with ultrafiltration, published reports have shown controversial findings. Differences in selection of the study population and in ultrafiltration indications and protocols, and high variability in the pharmacologic therapy used for the control group could explain some of these conflicting results. Here, we aimed to provide an overview on the current medical evidence supporting the use of ultrafiltration in AHF, with a special focus on the identification of potential candidates who may benefit the most from this therapeutic option.
\end{abstract}

Keywords: ultrafiltration, acute heart failure, fluid overload, diuretics

\section{Introduction}

Acute heart failure (AHF) is a major public health problem and the leading cause of hospitalization among patients aged $>65$ years, with the number of admissions expected to increase in the future. ${ }^{1,2}$ Moreover, it is associated with a poor prognosis, with more than $20 \%$ of patients being readmitted with AHF and more than $20 \%$ dying during the first year after admission. ${ }^{3,4}$ Volume overload is considered a hallmark of AHF, and almost all patients hospitalized with this disease show signs of fluid overload and organ congestion. Notably, both incomplete decongestion and recurrent congestion are closely associated with short-term and long-term outcomes, independently of age and of renal function. Thus, proper management of fluid overload in AHF represents a critical therapeutic target and an opportunity to improve overall outcome.

The key hemodynamic mechanisms involved in the development of fluid overload in AHF patients consist of the rise in central venous pressure, and the decrease in cardiac output and effective circulating volume associated with systolic and/or diastolic ventricular dysfunction. ${ }^{5-8}$ These hemodynamic changes negatively impact on renal function, by decreasing glomerular filtration rate (GFR), which elicits the compensatory activation of the renin-angiotensin-aldosterone system (RAAS). ${ }^{9} 10$ The latter, in turn, determines sodium reabsorption at proximal tubule level, reducing its delivery distally, where loop diuretics typically act (Figure 1). ${ }^{11}$ As a result, further water and salt retention occurs despite increase in diuretic dosage, perpetuating the vicious circle of cardio-renal dysfunction.
Correspondence: Giancarlo Marenzi Centro Cardiologico Monzino, Via Parea 4, 20138 Milan, Italy

Tel +3902580021

Fax +39025800 2287

Email giancarlo.marenzi@ccfm.it 

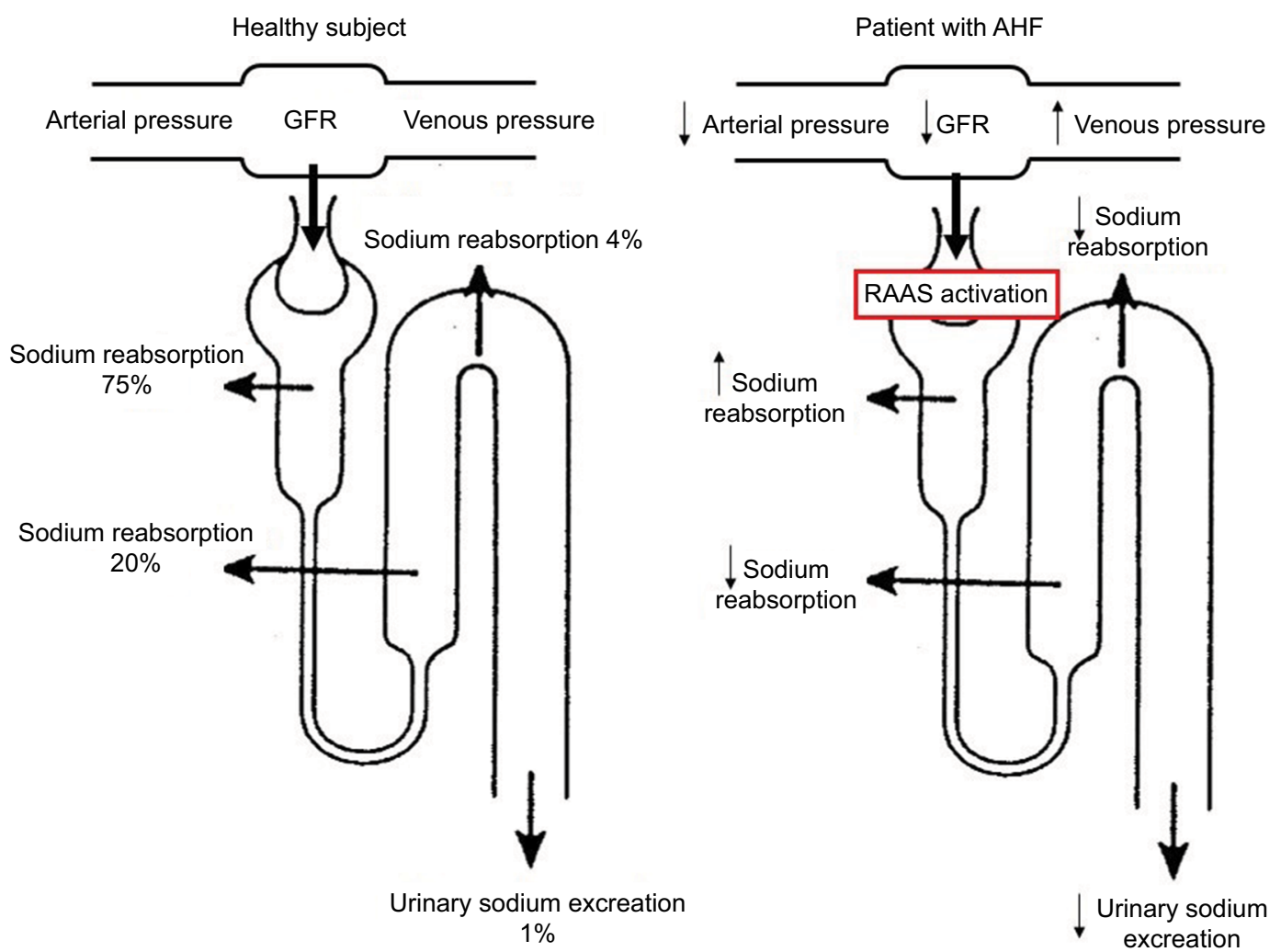

Figure I Schematic representation of the cascade of events leading to impaired urinary sodium excretion in AHF. Abbreviations: AHF, acute heart failure; GFR, glomerular filtration rate; RAAS, renin-angiotensin-aldosterone system.

The first pharmacological option recommended by current cardiologic guidelines for AHF with overt fluid overload is optimization of diuretic therapy to increase water and sodium elimination. ${ }^{12,13}$ Although intensive intravenous treatment with loop diuretics may initially enhance fluid loss and reduce left ventricular pressure, their use is associated with neuro-hormonal activation, intra-vascular volume depletion, and renal function worsening. Moreover, their efficacy decreases over time, a condition defined as "breaking phenomenon", with no further body weight loss or, even, achievement of a positive fluid balance despite diuretic administration. ${ }^{14,15}$ Accordingly, in AHF patients with poor diuretic response, rather than further increasing the diuretic dose, a more physiological approach could be used to correct the initial hemodynamic abnormalities. Extracorporeal ultrafiltration is a mechanical strategy for fluid removal that has been proposed for this purpose, and, although the underlying robust rationale, significant debate still remains about the best clinical indications and therapeutic protocols. ${ }^{16-18}$

The objective of the present review is to provide an overview of the mechanisms and the clinical effects of ultrafiltration and update the current evidence supporting its use in AHF, with a special focus on the identification of potential candidates who may benefit the most from such a therapeutic strategy.

\section{Technical aspects of ultrafiltration}

Ultrafiltration resembles glomerular filtration, a specific function of the kidney, and it represents the basic form of renal replacement therapy utilized for net fluid removal with minimal solute clearance and depurative effect. A Y-shaped double-lumen catheter, a peristaltic pump, and a filter inserted in a veno-venous extracorporeal circuit are used. The pump determines a negative pressure, thus allowing blood circulation in the circuit from a vein to the filter, and then back to the patient (Figure 2). The filter is made of highly permeable membranes that allow separation of water and low-molecularweight ( $<50,000$ daltons) solutes from blood. The pressure difference across the membrane is generated by the Starling forces (difference between hydrostatic pressure in the blood and that in the ultrafiltrate compartment, opposed to the oncotic pressure generated by plasma proteins), with the resulting transmembrane pressure gradient driving plasma water through the filter exactly as Starling forces operate in a capillary bed. During ultrafiltration, water and some solutes are passively removed by convective transport. The generated 


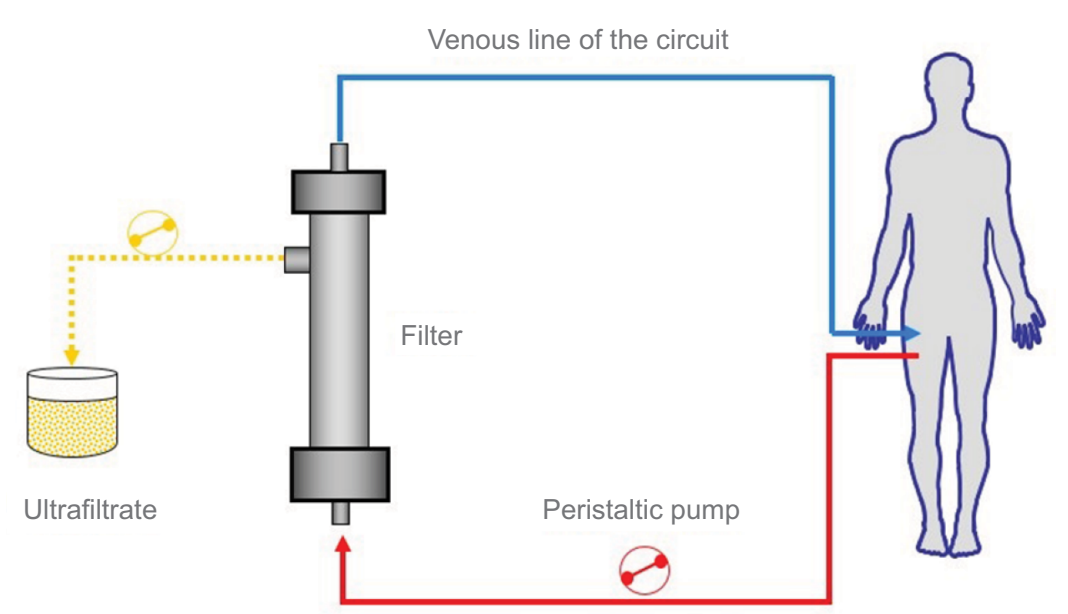

Arterial line of the circuit

Figure 2 Principle of ultrafiltration using a veno-venous extracorporeal circuit. Reproduced with permission Springer Am J Cardiovasc Drugs. Continuous ultrafiltration in acute decompensated heart failure: Current issues and future directions. 2015;15(2):103-112. Marenzi G, Morpurgo M, Agostoni P. ${ }^{17}$ (c) Springer International Publishing Switzerland 2015 with the permission of Springer.

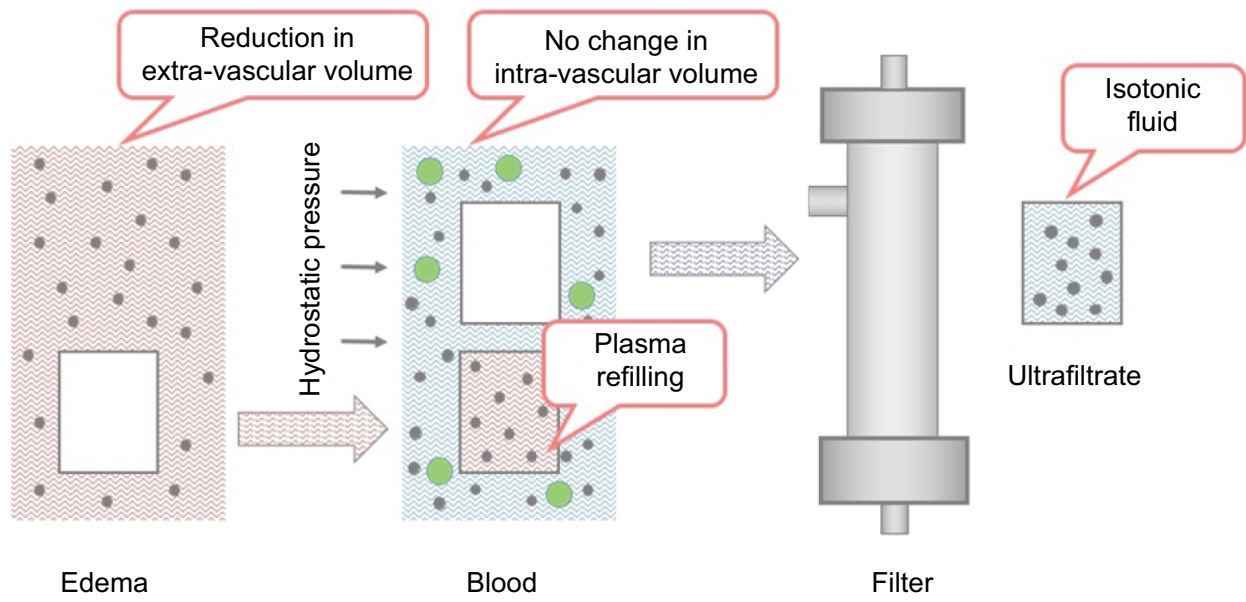

Proteins Small solutes $(<50,000 \mathrm{Da})$

Figure 3 Schematic exemplification of fluid volume shift between the extra-vascular and intra-vascular compartments during ultrafiltration.

ultrafiltrate has the same composition of plasma water (blood without proteins and blood corpuscolate elements), and is essentially isosmotic with blood. Therefore, the blood oncotic pressure increases, eliciting intra-vascular refilling from the interstitial compartment, with a parallel and real-time shift of fluid from the extra-vascular to the intra-vascular compartment (Figure 3). Circulating volume is safeguarded and systemic arterial hypotension prevented when fluid refilling replaces the removed intra-vascular fluid. ${ }^{19}$ When significant blood volume reduction occurs, ultrafiltration rate should be reduced or halted until a complete refilling from the interstitial compartment has taken place. Notably, in patients with ultrafiltration, non-invasive monitoring of intra-vascular volume can be easily performed through serial assessment, or continuous monitoring of hematocrit value, that should remain unchanged during treatment. ${ }^{19,20}$
Another important technical issue regards the coagulation of the extracorporeal circuit that may occur during ultrafiltration, particularly at the membrane level and at the venous bubble trap chamber. Therefore, strategies to prevent clot formation in the circuit are essential, and heparin administration is usually required. ${ }^{18}$

\section{Clinical effects of ultrafiltration}

The peculiar characteristics of ultrafiltration consist of eliminating excessive fluid from the extra-vascular space, without altering circulating volume and, consequently, without inducing neuro-hormonal activation and renal dysfunction. These properties lead to the beneficial clinical and hemodynamic effects related to ultrafiltration (Table 1). ${ }^{19,21,22}$ The reduction of extra-vascular lung water is associated with improvement in dyspnea, pulmonary gas exchanges, radiological signs of 
Table I Effects in hemodynamic, plasma, and urine parameters induced by ultrafiltration

\begin{tabular}{ll}
\hline Variable & Effect \\
\hline Heart rate (beats/min) & $=$ \\
Mean systemic arterial pressure $(\mathrm{mmHg})$ & $=$ \\
Mean pulmonary arterial pressure $(\mathrm{mmHg})$ & $\downarrow$ \\
Mean pulmonary wedge pressure $(\mathrm{mmHg})$ & $\downarrow$ \\
Mean right atrial pressure $(\mathrm{mmHg})$ & $\downarrow$ \\
Cardiac index $\left(\mathrm{L} / \mathrm{min} / \mathrm{m}^{2}\right)$ & $=$ \\
Renal perfusion pressure $(\mathrm{mmHg})$ & $\uparrow$ \\
Plasma norepinephrine $(\mathrm{pg} / \mathrm{mL})$ & $\downarrow$ \\
Plasma renin activity $(\mathrm{ng} / \mathrm{mL} / \mathrm{h})$ & $\downarrow$ \\
Plasma aldosterone $(\mathrm{pg} / \mathrm{mL})$ & $\downarrow$ \\
Plasma sodium concentration $(\mathrm{mEg} / \mathrm{L})$ & $=$ \\
Diuresis $(\mathrm{mL} / 24 \mathrm{~h})$ & $\uparrow$ \\
Urinary sodium concentration $(\mathrm{mEg} / \mathrm{L})$ & $\uparrow$ \\
\hline
\end{tabular}

Note: $\uparrow$, increase; $\downarrow$, decrease; =, unchanged.

pulmonary vascular congestion, and alveolar and interstitial edema. ${ }^{23-25}$ Moreover, the reduction of the intra-thoracic pressure due to extra-vascular lung water reabsorption has a beneficial effect on cardiac dynamics, improving its diastolic burden. ${ }^{26-28}$ On the other hand, removal of systemic extravascular fluid is associated with resolution of peripheral edema, also including ascites, pleural and pericardial effusions, when evident.

In addition to fluid removal and hemodynamic improvement, another major effect of ultrafiltration, particularly useful in patients with AHF, is the restoration of diuretic responsiveness. ${ }^{24,29,30}$ The mechanism by which ultrafiltration reestablishes an adequate urine output is still not completely understood, but it is possibly based on the following sequence of events: recovery of an effective arterial-venous pressure gradient across the kidney (due to reduction in central venous pressure without a parallel decrease in mean systemic arterial pressure), increased GFR, blunting of RAAS activity, and, as a result, increased sodium delivery to more distal nephron sites. This cascade of effects may explain the restoration of a favorable renal response to diuretic therapy and the maintained beneficial effects, in the following days and months after a single session of ultrafiltration, with a lower dosage of diuretics. Thus, ultrafiltration and diuretics are complementary therapeutic options, rather than alternative strategies. This is a critical point that may explain, at least in part, conflicting results among trials. ${ }^{31-38}$ The abrupt withdrawal of diuretics in AHF patients, who have been using them chronically, determines sodium retention and may limit the ultrafiltration's ability to remove a larger amount of sodium for a given volume of water, when compared to diuretics. Accordingly, in Chung et al.' $\mathrm{s}^{34}$ study, a lower urine sodium concentration was found in patients undergoing ultrafiltration, who were not treated with loop diuretics after randomization, compared to diuretic therapy. On the other hand, continuing diuretics during ultrafiltration seems to elicit urinary sodium excretion, restoring diuretic responsiveness. ${ }^{39}$ However, the majority of studies and meta-analyses, thus far performed, still opposed ultrafiltration compared to diuretics, highlighting that their complementary effect is not a shared view. ${ }^{40-42}$ It can be expected that an improved outcome could be reported when the two strategies are used in association. This concept is exemplified in Figure 4, where the response to ultrafiltration and diuretics, regarding cumulative sodium excretion, either alone or in combination, is shown.

Some studies, like the Cardiorenal Rescue Study in Acute Decompensated Heart Failure (CARRESS-HF) ${ }^{36}$ and the Aquapheresis versus Intravenous Diuretics and Hospitalization for Heart Failure (AVOID-HF) trials, ${ }^{35}$ have observed a higher frequency of adverse events in patients treated with ultrafiltration, raising some concerns regarding its safety. However, despite the fact that the need for a central venous catheter and anticoagulation may be associated with an increased risk of catheter infections and local bleeding, most of the side effects reported in these studies were due to unskilled use of extracorporeal therapy (i.e., worsening renal function due to excessive or too rapid fluid removal) or to clinical complications unrelated to the treatment (pneumonia, gastrointestinal hemorrhage, sepsis) but possibly associated with the underlying critical condition. Notably, the requirement for a central venous catheter and admission to the intensive care unit might be overcome by simplified device systems employing single peripheral venous access allowing a lower level of patient monitoring. ${ }^{43}$

\section{Selection of patients for ultrafiltration}

The non-homogeneous results of studies on the effects of ultrafiltration in the setting of AHF underscore that patient selection remains to be fully clarified. ${ }^{31-38}$ Current guidelines recommend ultrafiltration only when fluid overload persists despite the use of high-dose intravenous loop diuretics or the combination of different diuretic agents. ${ }^{12,13}$ However, the degree of resistance to medical therapy that should be achieved for implementing ultrafiltration, and the clinical, hemodynamic, and/or laboratory parameters that should be considered to identify this condition, are still unresolved questions. Of note, most of the studies on ultrafiltration in AHF patients have relied, as inclusion criteria and fluid 


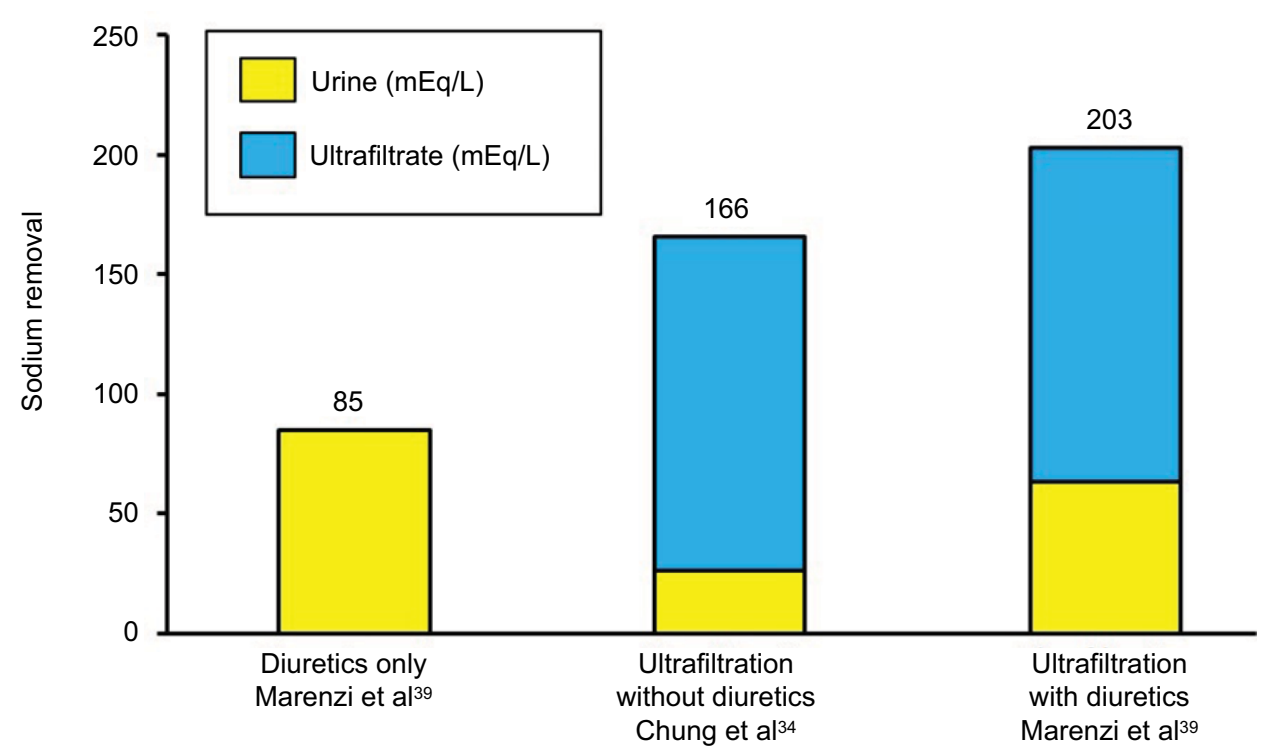

Figure 4 Sodium removal in acute heart failure patients treated with diuretics only, with ultrafiltration but without diuretics, and with the combination of ultrafiltration and diuretics.

removal targets, on clinical signs and symptoms of congestion; however, it is known that the correlation between clinical assessment and objective measures of congestion is marginal. ${ }^{44}$ Moreover, published studies differ in study population selection (in terms of baseline clinical characteristics, hemodynamic profile, and severity of renal functional impairment) and they are characterized by disparity of the indications for the use of ultrafiltration, heterogeneity in the ultrafiltration protocols, and high variability in the pharmacologic strategies used in the control group (Table 2) ${ }^{31-38} \mathrm{As}$ a result, study findings significantly diverge from each other, so that no firm conclusion can be currently drawn on the selection of the most appropriate candidate for ultrafiltration. Yet, some assumptions can be inferred from these reports and they may help the physicians to better identify AHF patients who may derive the greatest benefit from ultrafiltration. Most of the negative studies included patients with ongoing hemodynamic instability and/or acute kidney injury, and applied too aggressive or non-customized de-hydration protocols. For example, in the CARRESS-HF trial, ${ }^{36}$ patients with AHF were treated with ultrafiltration after development of acute kidney injury and the ultrafiltration rate was uniformly delivered at $200 \mathrm{~mL} / \mathrm{h}$ without being tailored to patients' clinical status. The fixed ultrafiltration rate and the lack of a prudential volume target might have led to an overly aggressive protocol in patients treated with ultrafiltration. Of note, in this trial, the first $48 \mathrm{~h}$ weight loss tended to be faster in the ultrafiltration group, potentially contributing to their renal function decline. Similarly, in the study by Patarroyo et al., ${ }^{45}$ ultrafiltration was initiated in patients who had possibly already developed acute kidney injury and had impending, or overt, cardiogenic shock (average cardiac index 1.8 [range 1.48 to 2.25 ] $\mathrm{L} / \mathrm{min} / \mathrm{m}^{2}$ ). Moreover, these patients underwent an excessive, or excessively fast (when compared with patients' plasma refilling rate capacity), fluid removal, with consequent hypovolemia (as reflected by total protein concentration increase during ultrafiltration) and further renal injury. Thus, in AHF patients experiencing acute kidney injury and/or hemodynamic instability, a more prudential, even if partial, fluid removal protocol should be adopted. Indeed, in these patients a slow dehydration approach will prevent hypovolemia and hypotension, preserving hemodynamic status and renal perfusion. Notably, a higher ultrafiltration rate was shown in patients experiencing acute kidney injury as compared with those not having acute kidney injury. ${ }^{46}$ This suggests that creatinine rise observed in patients treated with ultrafiltration can be considered an iatrogenic complication associated with a too aggressive fluid removal protocol. As worsening renal function is a strong predictor of clinical outcome in $\mathrm{AHF},{ }^{47}$ possibly mediated by neuro-hormonal activation, ${ }^{39}$ it should be carefully avoided by all means during ultrafiltration. Based on these considerations, acute kidney injury should not be considered a study endpoint of efficacy, like in the CARRESS-HF triali ${ }^{36}$ rather, it may be regarded as a marker of a not well-performed ultrafiltration treatment.

In other studies in which prompt adjustment of ultrafiltration rates in response to changes in clinical parameters was made, like in AVOID-HF trial or with 
Table 2 Overview of randomized ultrafiltration clinical trials

\begin{tabular}{|c|c|c|c|c|c|c|}
\hline Study (year) & $\begin{array}{l}\text { Sample } \\
\text { size }\end{array}$ & $\begin{array}{l}\text { Ultrafiltration } \\
\text { start prior to } \\
\text { rise in } \mathrm{sCr}\end{array}$ & $\begin{array}{l}\text { Diuretics } \\
\text { allowed } \\
\text { during UF }\end{array}$ & $\begin{array}{l}\text { Durationl } \\
\text { rate of } \\
\text { treatment } \\
\text { adjustable }\end{array}$ & Main findings & Impact on renal function \\
\hline $\begin{array}{l}\text { RAPID-CHF } \\
(2005)\end{array}$ & $\mathrm{N}=40$ & Yes & No & Yes & $\begin{array}{l}\text { - greater fluid removal with UF but } \\
\text { weight loss was similar in both } \\
\text { groups }\end{array}$ & $\begin{array}{l}\text { - no significant difference in } \\
\text { renal function between UF } \\
\text { and diuretic groups }\end{array}$ \\
\hline $\begin{array}{l}\text { UNLOAD } \\
(2007)\end{array}$ & $N=200$ & Yes & No & Yes & $\begin{array}{l}\text { greater net fluid loss with UF - } \\
\text { fewer patients in the UF group } \\
\text { were rehospitalized at } 90 \text { days with } \\
\text { no significant difference in renal } \\
\text { function between UF and diuretic } \\
\text { groups }\end{array}$ & $\begin{array}{l}\text { percentage of patients } \\
\text { with }>0.3 \mathrm{mg} / \mathrm{dL} \text { rise in } \\
\mathrm{sCr} \text { higher in UF group at } \\
24 \mathrm{~h}, 48 \mathrm{~h} \text {, and at discharge } \\
\text { (statistically not significant) }\end{array}$ \\
\hline $\begin{array}{l}\text { ULTRADISCO } \\
(2011) \\
\text { II }\end{array}$ & $\mathrm{N}=30$ & Yes & No & Yes & $\begin{array}{l}\text { - weight loss significantly greater in } \\
\text { the UF group } \\
\text { - UF resulted in reduction in } \\
\text { serum aldosterone levels and } \\
\text { systemic vascular resistance, and } \\
\text { improvement in cardiac index }\end{array}$ & $\begin{array}{l}\text { - no significant difference } \\
\text { was observed in sCr levels } \\
\text { between baseline and } \\
\text { post-therapy and between } \\
\text { diuretic and UF groups }\end{array}$ \\
\hline $\begin{array}{l}\text { CARRESS-HF }{ }^{33} \\
(2012)\end{array}$ & $N=188$ & No & No & No & $\begin{array}{l}\text { - weight loss was similar with UF and } \\
\text { diuretic therapy } \\
\text { - patients in UF group had higher rate } \\
\text { of adverse events }\end{array}$ & $\begin{array}{l}\text { - } s C r \text { level increased } \\
\text { significantly after UF, no } \\
\text { change in sCr level with } \\
\text { medical therapy }\end{array}$ \\
\hline $\begin{array}{l}\text { Hanna et }\left.a\right|^{38} \\
(2012)\end{array}$ & $\mathrm{N}=36$ & No & No & Yes & $\begin{array}{l}\text { - fluid removal was faster and more } \\
\text { efficient in the UF group with } \\
\text { shorter hospital length of stay } \\
\text { - no difference in hospital re- } \\
\text { admissions and emergency } \\
\text { department visits between the two } \\
\text { groups }\end{array}$ & $\begin{array}{l}\text { - no significant difference in } \\
\mathrm{s} C r \text { and cystatin- } \mathrm{C} \text { levels } \\
\text { before and after therapy } \\
\text { between the two groups }\end{array}$ \\
\hline $\begin{array}{l}\text { Chung et } \mathrm{a}^{34} \\
(2014)\end{array}$ & $N=16$ & No & No & Yes & $\begin{array}{l}\text { - no differences in total volumes, } \\
\text { sodium removed, lengths of hospital } \\
\text { stay, and short-term readmissions } \\
\text { between the two groups }\end{array}$ & $\begin{array}{l}\text { - the mean change in } \mathrm{sCr} \\
\text { between admission and } \\
\text { discharge did not differ } \\
\text { between the two groups }\end{array}$ \\
\hline $\begin{array}{l}\text { CUORE }^{37} \\
(2014)\end{array}$ & $\mathrm{N}=56$ & Yes & Yes & Yes & $\begin{array}{l}\text { despite similar body weight } \\
\text { reduction in the two groups, a lower } \\
\text { incidence of rehospitalizations for } \\
\text { HF was observed in the UF-treated } \\
\text { patients at I-year follow-up }\end{array}$ & $\begin{array}{l}\text { - no significant difference in } \\
\mathrm{sCr} \text { levels before and after } \\
\text { therapy between the two } \\
\text { groups }\end{array}$ \\
\hline $\begin{array}{l}\text { AVOID-HF }{ }^{35} \\
(2016)\end{array}$ & $\mathrm{N}=224$ & Yes & No & Yes & $\begin{array}{l}\text { - no significant difference between } \\
\text { the two groups in length of hospital } \\
\text { stay and in } 90 \text {-day mortality but } \\
\text { significantly lower rehospitalization } \\
\text { for acute HF at } 90 \text { days in the UF } \\
\text { group }\end{array}$ & $\begin{array}{l}\text { - no difference between the } \\
\text { two groups in terms of } \mathrm{sCr} \\
\text { and estimated glomerular } \\
\text { filtration rate during } \\
\text { treatment and up to } 90 \\
\text { days }\end{array}$ \\
\hline
\end{tabular}

Abbreviations: $\mathrm{sCr}$, serum creatinine; $\mathrm{HF}$, heart failure; UF, ultrafiltration.

hemodynamically-guided therapy, ${ }^{35}$ the risk of worsening renal function induced by hypovolemia was reduced. Accordingly, in the Continuous Ultrafiltration for Congestive Heart Failure (CUORE) trial, ${ }^{37}$ in which hematocrit was continuously monitored to guide ultrafiltration rate adjustments, and complete de-hydration was carefully avoided, ultrafiltration was associated with a more stable renal function, and with a lower incidence of rehospitalizations for AHF during the 1-year follow-up. Therefore, patients with AHF characterized by severe fluid overload, hemodynamic stability, and no evident response to optimized intravenous diuretic therapy, in terms of negative fluid balance, should be considered eligible for ultrafiltration. We believe that this indication can be particularly relevant in patients without concomitant severe renal insufficiency and with low urinary sodium concentration, despite diuretic dosage adequate to their GFR. In those 
with severe renal failure, other renal replacement therapy modalities, such as hemofiltration or hemodiafiltration, should be used with the goal of also removing solutes and re-equilibrating the acid-base status of the patient.

To date, no study has specifically investigated whether the response to ultrafiltration is similar in patients with different AHF etiologies (ischemic vs. non-ischemic) and/or clinical presentation (de novo AHF vs. re-exacerbation of chronic heart failure). However, ultrafiltration should not be employed indiscriminately in all AHF patients. Indeed, in those with de novo AHF, or not receiving daily diuretic therapy, fluid loss can be achieved with intravenous diuretics; therefore, these drugs should be used instead of ultrafiltration. ${ }^{18}$ In addition, to our knowledge, one study only compared the effects of ultrafiltration in AHF patients with systolic dysfunction and with preserved ejection fraction. ${ }^{48}$ Therapeutic responses in the two groups were similar, in terms of total weight loss, effect on electrolyte and renal parameters, and in-hospital mortality. This suggests that, regardless of the underlying etiology of AHF, ultrafiltration has reproducible effects by acting on the common final hemodynamic consequences of severe fluid overload.

\section{Future perspectives}

It is evident from the current medical literature that ultrafiltration should be reserved for the right candidate. Therefore, future research in this field should assess in which patients ultrafiltration may rapidly restore a complete diuretic response. In particular, it is plausible that ultrafiltration may be especially effective in patients whose urinary sodium concentration is low despite appropriate dose of loop diuretics. This hypothesis should be tested in well-designed studies, taking into account not only the absolute urinary sodium concentration but also its value indexed to the diuretic dose. In addition, they should examine whether a threshold of urinary sodium excretion can be identified, below which recovery of diuretic responsiveness and sustained clinical benefit can be anticipated with ultrafiltration. Information on ClinicalTrials.gov show that randomized trials and registries on ultrafiltration in AHF patients are ongoing or have just been completed. Therefore, their results may identify the clinical characteristics of patients who may greatly benefit from ultrafiltration, the most appropriate therapeutic protocol, in terms of safety and efficacy, and the impact of this treatment on hard clinical endpoints. Moreover, as previously mentioned, future studies should evaluate the potential advantages associated with the combined use of ultrafiltration and diuretics.

\section{Conclusion}

In patients with $\mathrm{AHF}$ and reduced diuretic responsiveness, ultrafiltration may modify the traditional pharmacological strategy and newer techniques and devices will facilitate this trend. Considering the aforementioned points, as well as the shortcomings of the trials on ultrafiltration, many questions remain unanswered about its use in AHF, including selection of the best candidates for the therapy, optimal fluid removal rates, and safety. Based on the current evidence, clinicians may consider ultrafiltration in their armamentarium against fluid overload and judiciously use it after careful evaluation of patients who fit within the narrow spectrum of true refractoriness to diuretics.

\section{Disclosure}

The authors report no conflicts of interest in this work.

\section{References}

1. Wier LM, Pfuntner A, Maeda J, et al. HCUP facts and figures: Statistics on hospital-based care in the United States, 2009. Rockville, MD: Agency for Healthcare Research and Quality; 2011.

2. Roger VL, Go AS, Lloyd-Jones DM, et al. Heart disease and stroke statistics--2012 update: a report from the American Heart Association. Circulation. 2012;125(1):e2-e220.

3. Lee DS, Mamdani MM, Austin PC, Gong Y, Liu PP, Rouleau JL, Tu JV. Trends in heart failure outcomes and pharmacotherapy: 1992 to 2000. Am J Med. 2004;116(9):581-589.

4. Solomon SD, Dobson J, Pocock S, et al. Influence of nonfatal hospitalization for heart failure on subsequent mortality in patients with chronic heart failure. Circulation. 2007;116(13):1482-1487.

5. Mullens W, Abrahams Z, Francis GS, et al. Importance of venous congestion for worsening of renal function in advanced decompensated heart failure. J Am Coll Cardiol. 2009;53(7):589-596.

6. Schrier RW. Pathogenesis of sodium and water retention in high-output and low-output cardiac failure, nephrotic syndrome, cirrhosis, and pregnancy (1). N Engl J Med. 1988;319(16):1065-1072.

7. Schrier RW. Pathogenesis of sodium and water retention in high-output and low-output cardiac failure, nephrotic syndrome, cirrhosis, and pregnancy (2). N Engl J Med. 1988;319(17):1127-1134.

8. Sica DA. Sodium and water retention in heart failure and diuretic therapy: basic mechanisms. Cleve Clin J Med. 2006;73 (Supp1 2):S2-S7.

9. McMurray JJ. Clinical practice. Systolic heart failure. $N$ Engl J Med. 2010;362(3):228-238.

10. Francis GS, Goldsmith SR, Levine TB, Olivari MT, Cohn JN. The neurohumoral axis in congestive heart failure. Ann Intern Med. 1984;101(3):370-377.

11. Koniari K, Parissis J, Paraskevaidis I, Anastasiou-Nana M. Treating volume overload in acutely decompensated heart failure: established and novel therapeutic approaches. Eur Heart J Acute Cardiovasc Care. 2012;1(3):256-268.

12. Ponikowski P, Voors AA, Anker SD, et al. 2016 ESC Guidelines for the diagnosis and treatment of acute and chronic heart failure: The Task Force for the diagnosis and treatment of acute and chronic heart failure of the European Society of Cardiology (ESC). Developed with the special contribution of the Heart Failure Association (HFA) of the ESC. Eur J Heart Fail. 2016;18(8):891-975.

13. Yancy CW, Jessup M, Bozkurt B, et al. 2013 ACCF/AHA guideline for the management of heart failure: a report of the American College of Cardiology Foundation/American Heart Association Task Force on Practice Guidelines. J Am Coll Cardiol. 2013;62(16):e147-e239. 
14. Ellison DH. Diuretic resistance: physiology and therapeutics. Semin Nephrol. 1999;19(6):581-597.

15. Palazzuoli A, Ruocco G, Ronco C, McCullough PA. Loop diuretics in acute heart failure: beyond the decongestive relief for the kidney. Crit Care. 2015;19:296.

16. Agostoni PG, Marenzi GC. Sustained benefit from ultrafiltration in moderate congestive heart failure. Cardiology. 2001;96(3-4):183-189.

17. Marenzi G, Morpurgo M, Agostoni P. Continuous ultrafiltration in acute decompensated heart failure: Current issues and future directions. Am $J$ Cardiovasc Drugs 2015; 15(2):103-112.

18. Costanzo MR, Ronco C, Abraham WT, et al. Extracorporeal ultrafiltration for fluid overload in heart failure: current status and prospects for further research. J Am Coll Cardiol. 2017;69(19):2428-2445.

19. Marenzi G, Lauri G, Grazi M, Assanelli E, Campodonico J, Agostoni P. Circulatory response to fluid overload removal by extracorporeal ultrafiltration in refractory congestive heart failure. $\mathrm{J} \mathrm{Am} \mathrm{Coll} \mathrm{Cardiol}$. 2001;38(4):963-968.

20. Schroeder KL, Sallustio JE, Ross EA. Continuous haematocrit monitoring during intradialytic hypotension: precipitous decline in plasma refill rates. Nephrol Dial Transplant. 2004;19(3):652-656.

21. Jain A, Agrawal N, Kazory A. Defining the role of ultrafiltration therapy in acute heart failure: a systematic review and meta-analysis. Heart Fail Rev. 2016;21(5):611-619.

22. Koratala A, Kazory A. Extracorporeal ultrafiltration for acute heart failure: lost battle or lasting opportunity? Blood Purif. 2017;43(1-3):1-10.

23. Silverstein ME, Ford CA, Lysaght MJ, Henderson LW. Treatment of severe fluid overload by ultrafiltration. $N$ Engl $J$ Med. 1974;291(15):747-751.

24. Rimondini A, Cipolla C, Della Bella P, Grazi S, Sisillo E, Susini G, Guazzi MD. Hemofiltration as short-term treatment for refractory congestive heart failure. Am J Med. 1987;83(1):43-48.

25. Canaud B, Leblanc M, Leray-Moragues H, Delmas S, Klouche K, Beraud JJ. Slow continuous and daily ultrafiltration for refractory congestive heart failure. Nephrol Dial Transplant. 1998;13 (Supp1 4):51-55.

26. Pepi M, Marenzi GC, Agostoni PG, et al. Sustained cardiac diastolic changes elicited by ultrafiltration in patients with moderate congestive heart failure: pathophysiological correlates. Br Heart J. 1993;70(2):135-140.

27. Agostoni PG, Marenzi G, Sganzerla P, et al. Lung-heart interaction as a substrate for the improvement in exercise capacity after body fluid volume depletion in moderate congestive heart failure. Am J Cardiol. 1995;76(11):793-798.

28. Agostoni PG, Marenzi G, Pepi M, et al. Isolated ultrafiltration in moderate congestive heart failure. J Am Coll Cardiol. 1993;21(2):424-431.

29. Cipolla CM, Grazi S, Rimondini A, Susini G, Guazzi M, Della Bella P, Guazzi MD. Changes in circulating norepinephrine with hemofiltration in advanced congestive heart failure. Am J Cardiol. 1990;66(12):987-994.

30. Agostoni P, Marenzi G, Lauri G, Perego G, Schianni M, Sganzerla P, Guazzi MD. Sustained improvement in functional capacity after removal of body fluid with isolated ultrafiltration in chronic cardiac insufficiency: failure of furosemide to provide the same result. Am J Med. 1994;96(3):191-199.

31. Giglioli C, Landi D, Cecchi E, et al. Effects of ultrafiltration vs. diuretics on clinical, biohumoral and haemodynamic variables in patients with decompensated heart failure: the ULTRADISCO study. Eur J Heart Fail. 2011;13(3):337-346.

Vascular Health and Risk Management

\section{Publish your work in this journal}

Vascular Health and Risk Management is an international, peerreviewed journal of therapeutics and risk management, focusing on concise rapid reporting of clinical studies on the processes involved in the maintenance of vascular health; the monitoring, prevention and treatment of vascular disease and its sequelae; and the involvement of
32. Bart BA, Boyle A, Bank AJ, et al. Ultrafiltration versus usual care for hospitalized patients with heart failure: the Relief for Acutely FluidOverloaded Patients With Decompensated Congestive Heart Failure (RAPIDCHF) trial. J Am Coll Cardiol. 2005;46(11):2043-2046.

33. Costanzo MR, Saltzberg MT, Jessup M, et al. Ultrafiltration is associated with fewer rehospitalizations than continuous diuretic infusion in patients with decompensated heart failure: results from UNLOAD. $J$ Card Fail. 2010;16(4):277-284.

34. Chung ES, O'Brien TM, Menon S, Bartone C, Mazur W, Kereiakes DJ. A pilot study of target weight guided treatment in acute heart failure using ultrafiltration or usual care: effect on sodium removal. Korean Circ J. 2014;44(3):156-161.

35. Costanzo MR, Negoianu D, Jaski BE, et al. Aquapheresis versus intravenous diuretics and hospitalizations for heart failure. JACC Heart Fail. 2016;4(2):95-105.

36. Bart BA, Goldsmith SR, Lee KL, et al. Ultrafiltration in decompensated heart failure with cardiorenal syndrome. $N$ Engl J Med. 2012; 367(24):2296-2304.

37. Marenzi G, Muratori M, Cosentino ER, et al. Continuous ultrafiltration for congestive heart failure: the CUORE trial. J Card Fail. 2014;20(1):9-17.

38. Hanna MA, Tang WH, Teo BW, et al. Extracorporeal ultrafiltration vs. conventional diuretic therapy in advanced decompensated heart failure. Congest Heart Fail. 2012;18(1):54-63.

39. Marenzi G, Grazi S, Giraldi F, et al. Interrelation of humoral factors, hemodynamics, and fluid and salt metabolism in congestive heart failure: effects of extracorporeal ultrafiltration. Am J Med. 1993;94(1):49-56.

40. Qi Zhi Q, Liang JC. Diuretics and ultrafiltration in acute heart failure syndrome. Int Heart J. 2013;54(6):390-394.

41. Kwong JS, Yu CM. Ultrafiltration for acute decompensated heart failure: A systematic review and meta-analysis of randomized controlled trials. Int J Cardiol. 2014;172(6):395-402.

42. Kwok CS, Wong CW, Rushton CA, et al. Ultrafiltration for acute decompensated cardiac failure: a systematic review and meta-analysis. Int J Cardiol. 2017;228:122-128.

43. Morpurgo M, Pasqualini M, Brunazzi MC, et al. A multicenter feasibility study on ultrafiltration via a single peripheral venous access in acute heart failure with overt fluid overload. Int J Cardiol. 2017;240:253-257.

44. Stevenson LW, Perloff JK. The limited reliability of physical signs for estimating hemodynamics in chronic heart failure. JAMA. 1989;261(6):884-888.

45. Patarroyo M, Wehbe E, Hanna M, Taylor DO, Starling RC, Demirjian S, Tang WH. Cardiorenal outcomes after slow continuous ultrafiltration therapy in refractory patients with advanced decompensated heart failure. J Am Coll Cardiol. 2012;60(19):1906-1912.

46. Raichlin E, Haglund NA, Dumitru I, et al. Worsening renal function in patients with acute decompensated heart failure treated with ultrafiltration: predictors and outcomes. J Card Fail. 2014;20(5):376.e25-e32.

47. Damman K, Navis G, Voors AA, et al. Worsening renal function and prognosis in heart failure: systematic review and meta-analysis. $J$ Card Fail. 2007;13(8):599-608.

48. Jefferies JL, Bartone C, Menon S, Egnaczyk GF, O’Brien TM, Chung ES. Ultrafiltration in heart failure with preserved ejection fraction: comparison with systolic heart failure patients. Circ Heart Fail. 2013; 6(4):733-739.

\section{Dovepress}

metabolic disorders, particularly diabetes. This journal is indexed on PubMed Central and MedLine. The manuscript management system is completely online and includes a very quick and fair peer-review system, which is all easy to use. Visit http://www.dovepress.com/ testimonials.php to read real quotes from published authors. 